\title{
Psychological distress among cancer survivors during implementation of a nationwide Movement Control Order over the COVID-19 pandemic
}

Li Ping Wong ( $\sim$ wonglp@ummc.edu.my )

University of Malaya https://orcid.org/0000-0002-0107-0532

Lee Lee Lai

University of Malaya

Mee Hoong See

University of Malaya

Haridah Alias

University of Malaya

Mahmoud Danaee

University of Malaya

Chuo Yew Ting

University of Malaya

Peter Seah Keng Tok

University of Malaya

\section{Research Article}

Keywords: cancer survivors, COVID-19 pandemic, psychological distress

Posted Date: August 26th, 2020

DOl: https://doi.org/10.21203/rs.3.rs-64258/v1

License: (9) (i) This work is licensed under a Creative Commons Attribution 4.0 International License.

Read Full License 


\section{Abstract}

Purpose: This study aimed to investigate the psychological distress and its associated factors among cancer survivors in Malaysia during the COVID-19 pandemic.

Methods: An anonymous Internet-based study was conducted between 23 April and 26 June 2020. During the study period, the country underwent Phase 3 and Phase 4 of the Movement Control Order (MCO), Conditional Movement Control Order (CMCO), and Recovery Movement Control Order (RMCO). Psychological distress was measured using the Hospital Anxiety and Depression Scale (HADS), which is a 14-item self-assessment scale for measuring distress (total HADS score (HADS-T)) with two subscales, namely anxiety (HADS-A) and depression (HADS-D).

Results: From a total of 631 responses received, the proportion of participants with abnormal anxiety and depression was $29.0 \%$ and $20.9 \%$, respectively. Distress was reported in $23.0 \%$ of the respondents. A total of $16.45 \%$ had combined abnormal anxiety and depression. The highest HADS-A $(6.10 ; 95 \% \mathrm{Cl} 5.64-$ 6.56), HADS-D (5.61; 95\% Cl 5.14-6.08), and HADS-T (11.71; 95\% Cl 10.84-12.58) scores were reported among respondents during Phase 4 of the MCO. Partial least squares-based structural equation modelling (PLS-SEM) revealed that self-perceived health status, perceived susceptibility, and severity of COVID-19 have the greatest effect, leading to higher HADS-A, HADS-D, and HADS-T scores.

Conclusion: Heightened psychological distress was evident in cancer survivors particularly during the enforcement of the MCO over COVID-19. Providing support to address cancer survivors' psychological and emotional needs during the COVID-19 pandemic is essential.

Implication for cancer survivors: Cancer survivors or their carers should be made aware of the high psychological risk during infectious disease outbreaks and seek timely support.

\section{Introduction}

The outbreak of coronavirus disease 2019 (COVID-19) in Wuhan, China in late December of 2019, caused by the severe acute respiratory syndrome coronavirus 2 (SARS-CoV-2) [1,2], has spread rapidly within China, to other neighbouring countries in Asia and beyond. In Malaysia, the SARS-CoV-2 infection was first reported on 25 January 2020. Nonetheless, the number of cases was relatively low for over a month and cases were mainly confined to imported ones. Localized clusters began to be found in early March and by 17 March the number of confirmed cases in Malaysia had reached 673; this is also the date when the first two fatalities was reported in the country. Subsequently, a nationwide Movement Control Order (MCO) to prevent further spread of the coronavirus was implemented on 18 March. By end of March, Malaysia had the largest cumulative confirmed number of coronavirus cases in South-East Asia [3]. In Malaysia, the MCO order included the closure of schools and higher education institutions, and "nonessential" businesses, as well as a general prohibition of mass movements and gatherings across the 
country including religious, sports, social, and cultural activities. Since then, the country has gone through the four MCO phases, with all the strict actions recommended by the World Health Organization (WHO) to contain the COVID-19 outbreak. A Conditional Movement Control Order (CMCO) was implemented from 13 May to 9 June, and a Recovery Movement Control Order (RMCO) took effect from 10th June and will last until 31 August with more lenient restrictions.

Cancer diagnosis and treatment represent significant stressors and a traumatizing event for many patients. The COVID-19 outbreak has resulted in additional psychological distress for both cancer patients and the survivors of cancer, which can be particularly harmful and require clinical prioritization. For most patients, whose immune systems may already be compromised, psychological distress associated with the pandemic may further weaken their immune system [4]. Secondly, people who are immunocompromised, whether caused by the disease itself or the treatment, have increased risk of SARS-CoV-2 infection compared with the general population $[5,6]$. Further, there is also evidence showing that cancer history confers the highest risk of severe complications and is correlated with poorer outcomes from SARS-CoV-2 infections [7]. Therefore, cancer patients and cancer survivors pose unique management dilemmas during infectious disease pandemics like COVID-19.

According to the Malaysia National Cancer Registry Report (MNCRR) 2012-2016, cancer cases in Malaysia have been increasing for the past 10 years, and it remains the second-highest cause of death [8]. It was reported that cancer cases in Malaysia increased to 115,238 from 2012 to 2016, compared to 103,507 from 2007 to 2011 [8]. Due to the growing number of cancer cases, and in addition to advances in early detection and improved cancer treatment that increased the life expectancy of cancer patients, the number of cancer survivors in Malaysia is large. Therefore, the psychological burden among cancer survivors in Malaysia during the COVID-19 pandemic warrants investigation. It is important to regularly assess their psychological status and facilitate timely intervention when necessary.

In summary, the primary objectives of the present study were to examine the psychological distress of people who have survived cancer during the COVID-19 outbreak in Malaysia. Factors such as sociodemographics, the characteristics of cancer [9,10], and the risk perception of COVID-19 [11] can affect psychological distress during the pandemic. Thus, understanding the extent to which these factors influence psychological distress will also be investigated.

\section{Methods}

An anonymous Internet-based study was conducted between 23 April and 26 June 2020. The data collection period, the trend of the confirmed COVID-19 cases in Malaysia, and MOC phases are shown in Figure 1. Inclusion criteria for this study were as follows: (1) being older than 18 years of age; (2) having at least 2 years of diagnosis; (3) currently not receiving treatment except for endocrine therapy, and (4) being a Malaysian citizen. The researchers used social network platforms (Facebook, Instagram, and WhatsApp) to disseminate and advertise the survey link. The survey link was also sent to members of community-based cancer support groups. All respondents were informed that their participation was 
voluntary. Informed consent was obtained using an online consent form that each participant had to actively agree to sign.

\section{Instruments}

The survey consisted of sections of questions that assessed: 1) socio-demographic background, characteristics of cancer, perceived health status; 2) perceived threat of the coronavirus infection; and 3) psychological distress measured using the Hospital Anxiety and Depression Scale (HADS).

Personal details, including age, gender, ethnicity, educational level, and average monthly household income, were queried. Baseline information about cancer characteristics, namely time since cancer diagnosis, type of cancer, stage of cancer at the time of first diagnosis, and type of cancer treatment received and co-morbidities, were queried. Overall perceived health is a subjective, individualized selfassessment of the current overall state of personal health and was measured by a single question asking for a rating of current general health status using four item choices ('excellent', 'good', 'fair', or 'poor').

We used the Health Belief Model, which explores two dimensions: perceived susceptibility (three-item questions) and perceived severity (three-item questions). The combination of perceived susceptibility and severity is referred to as 'perceived threat', and is one of the core constructs in the Health Belief Model [12-14]. The response options were 'strongly agree', 'agree', 'disagree', or 'strongly disagree'.

Psychological distress was measured using the Hospital Anxiety and Depression Scale (HADS) [15]. The HADS is a valid and reliable self-rating scale that measures anxiety and depression in both hospitals and communities. HADS is the most extensively validated scale for screening emotional distress in cancer patients [16]. It is a 14-item scale with seven items each for anxiety and depression subscales. Each of the subscales, namely HADS-A (anxiety) and HADS-D (depression), consists of seven items, and both of them had scores ranging from 0 (no problems) to 3 (maximum distress) resulting in a sum score ranging from 0 to 21 for both anxiety and depression. For HADS-A and HADS-D, a subscale score $>8$ denotes anxiety or depression, and a HADS total score (HADS-T) $>16$ denotes psychological distress. [15]. The questionnaire is available in two different languages, English and Bahasa Malaysia, the native language in Malaysia. The original HADS questionnaire in English was translated into Bahasa Malaysia. A standard forward and back-translation procedure was followed.

\section{Ethical considerations}

This study was approved by the University of Malaya Research Ethics Committee (UMREC). Approval code: UM.TNC2/UMREC - 885

\section{Statistical analyses}

Descriptive statistics were performed for continuous variables, and frequency distribution and $95 \%$ confidence interval were used to define the distribution of categorical variables. An independent sample $t$ - 
test was used to find the difference in means between two groups. One-way analysis of variance was used to determine whether there is any significant difference in mean among various groups.

Partial least squares structural equation modelling (PLS-SEM) was used to predict factors influencing HADS-A, HADS-D, and HADS-T. This technique assesses the reliability of the data set, the statistical significance of the coefficients, and the error of the estimated path coefficients [17]. The bootstrapped significance calculation was performed in SmartPLS software version 3.2.8 (SmartPLS GmbH) [18]. Prior to running the path model, the construct validity (convergent and discriminant) was tested. In the PLSSEM model, HADS (with two subscales), perceived susceptibility and severity were considered as reflective constructs, and all other independent variables were single-item constructs. Results of the measurement model indicated that all indicators had an acceptable outer loading $(>0.5)$ with a CR (composite reliability) value of more than 0.7 and an AVE (average variance extracted) above 0.5 . The variance inflation factors (VIFs) for all indicators were below 2.5, which revealed that all indicators belonging to these two constructs were adequately independent. Discriminant validity assessment through the heterotrait-monotrait (HTMT) ratio of correlations method also indicated that all HTMT values were lower than the most restrictive threshold (0.85) proposed by Kline (2011) [19], thereby indicating adequate discriminant validity.

\section{Results}

A total of 631 responses were received and analysed. Participants' ages ranged from 21 to 86 years $($ mean $=56.98, S D=11.21)$. As shown in Table 1 , according to demographics, the majority of

the study participants were females (72.4\%), of Chinese ethnicity (52.6\%). Nearly two-thirds were college or university graduates (64.3\%) and the highest proportion had incomes of MYR4000-8000. Almost an equal number of participants had been diagnosed with cancer for four years and below $(40.3 \%)$ and between five and nine years (40.6\%). The vast majority of the participants were survivors of breast $(61.8 \%)$ and prostate $(25.8 \%)$ cancer. The majority were in stage $2(39.0 \%)$ and stage $1(30.1 \%)$ of cancer at the time of first diagnosis. In regard to treatment received, most of them had undergone surgery (90.5\%), followed by chemotherapy (64.0\%). Only $31.7 \%$ reported having been diagnosed with another chronic disease (or diseases) and $36.9 \%$ reported that their health status was fair/poor.

Findings on perceived susceptibility showed that slightly more than half reported that they strongly agreed/agreed that their chances of getting coronavirus disease are great (53.4\%), and getting the coronavirus disease is possible (57.7\%). A higher proportion reported strongly agreeing/agreeing that they are worried about getting the coronavirus disease (70.0\%). In regard to perceived severity, a high proportion reported strongly agreeing/agreeing that complications from the coronavirus disease are serious (95.7\%), that they will be very sick if they catch the coronavirus disease (82.9\%), and that they are afraid of getting the coronavirus disease (89.5\%)

HADS scores by demographics and phases of $\mathrm{MCO}$ 
The mean HADS-Anxiety and HADS-Depression scores for the study participants were $5.54( \pm 3.87)$ and 4.51 ( \pm 3.70$)$, respectively. The mean HADS-Total score was 9.96 ( \pm 7.01$)$. In total, 29.0\% (95\% Cl 25.532.7 ) reported a HADS-Anxiety score > 8, and 20.8\% (95\% Cl 17.7-24.1) had a HADS-Depression score > 8. Of these, 104 participants $(16.5 \%, 95 \% \mathrm{Cl} 13.7-17.6)$ had combined anxiety and depression (both HADS-A and HADS-D scores > 8). A total of 22.3\% (95\% CI 19.2-25.8) reported a HADS-T score > 16. As shown in Table 1, mean HADS-A scores were significantly higher in participants with the highest secondary school education or below than those with college or university degrees.

The mean score of the anxiety subscale, HADS-A, was also significantly higher among those with an average household income of MYR4001-8000. By ethnicity, the mean HADS-A scores were higher among the Indian and the indigenous groups of Sabah or Sarawak. Mean HADS-D scores increase with increasing age and were significantly higher in males (5.51 \pm 3.86$)$ than females (4.01 \pm 3.56). Similarly, HADS-D scores were highest among the indigenous groups of Sabah or Sarawak (7.01 \pm 4.25), in participants with the highest secondary school education (5.57 \pm 4.26$)$, and among those with an average household income of MYR4001-8000 (4.85 \pm 3.76$)$. Similar differences were observed in the mean HADS-T scores by demographic characteristics.

Figure 2 shows the distribution of mean HADS-A, HADS-D, and HADS-T scores by phases of MCO. The highest HADS-A (6.10; 95\% Cl 5.64-6.56), HADS-D (5.61; 95\% Cl 5.14-6.08), and HADS-T (11.71; $95 \% \mathrm{Cl}$ 10.84-12.58) scores were reported among respondents during phase 3 of the MCO. A reduction in mean scores was observed during the CMCO and RMCO phases. A greater gradient of increase in the trend line slope was observed in HADS-D and HADS-T from phase 3 to phase $4 \mathrm{CMO}$, and similarly a higher gradient decrease in the trend line was observed from phase $4 \mathrm{MCO}$ to the CMCO/RMCO phases.

\section{HADS scores by cancer types and treatment history}

There are no significant differences in the mean HADS-A, HADS-D, and HADS-T scores by time since cancer diagnosis. However, the highest mean HADS-A, HADS-D, and HADS-T scores were recorded among participants who were at stage 4 of cancer at the time of first diagnosis. The mean HADS-A, HADS-D, and HADS-T scores increased as the stage of cancer at the time of first diagnosis increased. Participants who had bladder cancer reported the highest mean HADS-A, HADS-D, and HADS-T scores. Participants who have received chemotherapy reported the highest mean HADS-A (6.12 \pm 3.92$)$, HADS-D (4.96 \pm 3.96$)$, and HADS-T (11.08 \pm 7.26$)$ scores.

HADS scores by chronic diseases and health status

The mean HADS-A, HADS-D, and HADS-T scores were significantly higher in participants who reported having other chronic diseases. There was a significant increase in the mean HADS-A, HADS-D, and HADST scores as the overall health status decreased. The mean HADS-A (10.58 \pm 3.84$)$, HADS-D (12.13 \pm 3.12$)$, and HADS-T $(22.71 \pm 5.77)$ scores exceeded the threshold scores denoted for anxiety, depression, and psychological distress. 


\section{HADS by risk perception}

As shown in Table 1, all the participants who said they strongly agreed/agreed with all the perceived susceptibility and severity items reported higher mean HADS-A, HADS-D, and HADS-T scores than those who strongly disagreed/disagreed.

\section{Factors predicting HADS on PLS-SEM}

The PLS-SEM in Figure 2 shows the hypothesized associations for all the factors associated with HADS$A$ and HADS-D scores. Among all the factors, health status $(B=0.361, p<0.001)$, perceived susceptibility $(B=0.216, p<0.001)$, and perceived severity $(B=0.142, p<0.001)$ have the greatest effect on a higher HADS-A score. Stage of cancer $(B=0.110, p=0.002)$ and ethnicity $(B=0.068, p<0.03)$ are also

significant factors with a smaller effect in predicting a higher HADS-A score. The results for adjusted $\mathrm{R}^{2}$ indicated that this model explained $33.3 \%$ of the total variance in HADS-A.

For the association between the hypothesized factors and HADS-D, likewise health status $(B=0.451, p<$ $0.001)$, perceived susceptibility $(B=0.177, p<0.001)$, and severity $(B=0.083, p=0.011)$ showed the greatest effect in influencing higher HADS-D scores. Income $(B=-0.064, p=0.033)$ is inversely associated with a higher HADS-D score, whereas being female $(B=-0.085, p=0.016)$ is associated with a higher HADS-D. The results for adjusted $R^{2}$ indicated that this model explained $41.4 \%$ of the total variance in HADS-D.

The PLS-SEM in Figure 3 shows the hypothesized associations of all the factors associated with HADS-T. As depicted in the figure, health status $(B=0.437, p<0.001)$, perceived susceptibility $(B=0.212, p<$ $0.001)$, and severity $(B=0.122, p=0.001)$ showed the greatest effect in influencing a higher HADS-T score. A higher cancer stage $(B=0.081, p=0.011)$ is associated with a higher HADS-T score. Ethnicity ( $B$ $=0.064, p=0.033$ ) shows a weak and significant association with HADS-T. The results for adjusted $\mathrm{R}^{2}$ indicated that this model explained $41.1 \%$ of the total variance in HADS-A.

\section{Discussion}

COVID-19 is an emerging infectious disease that poses a significant threat to people who have survived cancer. Given the serious threats imposed by COVID-19, people who have survived cancer face a time of unprecedented fear and anxiety that may increase an existing threat. This study assesses psychological distress among cancer survivors and responses were captured through phases 3 and 4 of the MCO, throughout the entire CMCO, and in the early phase of the RMCO. Understanding the extent to which cancer survivors show psychological impairment during the COVID-19 pandemic is important in preventing it or treating its consequences.

The HADS-A score demonstrated that $29.0 \%$ of the study participants had anxiety, whereas a slightly lower proportion (20.9\%) demonstrated an abnormal level of depression based on HADS-D scores. Based on the HADS-T score, a total of $23.3 \%$ demonstrated psychological distress. The proportion of abnormal 
anxiety and depression found among the participants in this study is higher than that reported in a recent study on cancer patients in the United states, which indicated that a total of $23.3 \%$ demonstrated HADS-A and only 7.6\% HDAS-D above abnormal levels during the COVID-19 pandemic [20]. The low psychological impact among cancer patients in the US study was reported as probably being due to the fact that a high proportion of them are users of the counselling (56\%) and networking services $(80 \%)$ provided [20]. Also, the study was conducted at a time when the number of local confirmed cases in the US was low. Nonetheless, this suggests that psychological distress screening is essential and both survivors and cancer patients should be provided with guidance and counselling on adapting during the pandemic $[20,21]$. In Malaysia, a helpline providing counselling services to support people experiencing emotional distress during the COVID-19 pandemic is available [22]; however, the counselling services are for the general public and not specifically for cancer patients or survivors. This current study unfortunately did not gather information about the use of counselling service among our study participants.

The current study provides an overview of the trend of anxiety, depression, and psychological distress across the different phases of the MCO in Malaysia. The MCO, first imposed on 18 March, was extended until 9 June 2020. The four phases of the MCO have lasted 14 days each. Religious, sports, social, and cultural activity restrictions, social distancing and a loss of social cohesion, interstate travel bans, travel restrictions, and financial hardship due to job loss or reduced income associated with the shutdown of many industries during the implementation of the MCO have resulted in an increasing psychological impact across the four phases of the MCO. The extensions and prolonged MCO period have resulted in high psychological distress among the participants in the four phases of the MCO. However, in the CMCO and RMCO phases, a decrease in the trend line of anxiety, depression, and psychological distress was observed when some restrictions were lifted, and businesses reopened. It is worth noting that the greater gradient in the increase and decrease of the depression trend line compared to anxiety may imply that cancer survivors were more at risk of depression disorder during the MCO period.

Previous findings on the association of anxiety and depression with age in cancer patients have been mixed. In a study on a geriatric oncology population, while increased age was significantly associated with reduced anxiety, it was also associated with greater depressive symptoms [23]. There has also been a report that as age increased, anxiety decreased significantly; however, age was not a significant predictor of depression [24]. A study on anxiety and depression in working-age cancer survivors reported that higher anxiety was associated with younger age; nonetheless, no significant association between depression and age was found [25]. In our study there was no significant difference between anxiety and age; nevertheless, significant increases in depression and psychological distress were reported as age increased in the univariate analyses. However, in the PLS-SEM, age is not a significant predictor of anxiety, depression, or psychological distress. It is well documented that females are more likely than males to develop anxiety disorder [26]. Most studies on the general public reported higher anxiety and psychological impact in females than males during the COVID-19 pandemic [27-28], including a study in Malaysia [30]. Likewise, in this study, while gender is not a significant predictor of anxiety, the structural model indicated that being female is significantly associated with higher depression. Ethnicity, 
on the other hand, is a significant predictor of anxiety but not depression. It is worth noting that in the study, the Chinese reported the lowest anxiety and depression scores, whereas the highest scores were reported among the Indian and the indigenous groups from Sabah or Sarawak. In this study, the level of educational attainment is not a significant predictor of anxiety, depression, or psychological distress in all three structural equation modellings; nevertheless, in the univariate analyses, the scores for anxiety, depression, and psychological distress were significantly higher among survivors of lower educational attainment. A previous study reported that a higher educational level seems to have a protective effect against anxiety and depression across the lifespan [31]. This study also found that low level of income was significant and associated with depression in the structural equation modelling, likewise found in other studies. [32,33]. The findings of this study provide insights into the demographics of cancer survivors who are at higher risk of mental illness to effectively target the provision of behavioural counselling intervention.

The stage of cancer at diagnosis and co-morbidities (both before and after the cancer diagnosis) have been reported to affect the mental health and quality of life of cancer survivors [9]. Similarly, the findings of this study show that during the COVID-19 pandemic, the stage of cancer at diagnosis was significantly associated with anxiety and psychological distress but not depression. In regard to the influence of comorbidities, our study revealed that co-morbidities were not associated with anxiety, depression, or psychological distress. Overall perceived health is recognized as a powerful predictor of negative health outcomes and low health-related quality of life $[34,35]$. The PLS-SEM path analyses in this study revealed that overall perceived health was the strongest predictor of anxiety, depression, and psychological distress. Our findings suggest that interventions that aim to adjust patients' illness perceptions to facilitate a reduction of psychological distress during the COVID-19 pandemic are needed. As selfperceived health status is the assessment of narrative belief, there is also a need to further investigate cancer survivors' experiences and the actual physical health conditions underlying their self-reported health perceptions. As noted earlier, co-morbidities, which were also self-reported, were found to be not associated with anxiety, depression, or psychological distress.

The widespread media coverage and reports concerning older people and people who have underlying medical conditions being at increased risk of severe illness from COVID-19 have perhaps led to many of the cancer survivors in this study reporting a high-risk perception of COVID-19. We also found a particularly strong positive association between risk perception and anxiety, depression, and psychological distress. The participants with more intense perceived susceptibility and severity showing higher psychological distress found in this study were similar to those reported in a previous study on the Malaysian general population, where risk perception was found to enhance anxiety as measured by the State-Trait Anxiety Inventory (STAI) [30]. Hence, the findings imply the need to establish proper and effective risk communication surrounding COVID-19 to avoid causing psychological distress amongst cancer survivors during the pandemic.

Our study presents some evident limitations, which may have influenced the reporting of the results. Firstly, the key disadvantage of a cross-sectional online survey is that our sample may lack 
generalizability of the cancer survivor population in Malaysia. Nonetheless, our participant sample population consisted of well-distributed diversity in terms of demographics and illness conditions. Second, the responses were based on self-reports and may be subject to recall bias, self-reporting bias, and a tendency to report socially desirable responses. It is also important to note that the survey was conducted after the peak of COVID-19 in Malaysia. The study findings, therefore, have to be interpreted with caution.

\section{Conclusion}

The mental health of cancer survivors warrants the provision of psychological support during the COVID19 pandemic. In particular, we highlight that during quarantine or restriction of movement enforcement, psychological distress among cancer survivors increased along with the increased duration of the restriction. Hence, findings suggest that there is an essential need for cancer survivors or their carers to regularly monitor their psychological status during infectious disease pandemic and to facilitate timely intervention. Appropriate risk perception communication is warranted for people who are immunocompromised, such as cancer survivors, in order not to cause unnecessary panic. Individual characteristics such as socio-economic and co-morbid health conditions, and characteristics of cancer that are associated with psychological distress found in this study, offer insights into high-risk cancer survivors in terms of mental health screening, monitoring, and support.

\section{Declarations}

\section{Ethics approval}

This study was approved by the University of Malaya Research Ethics Committee (UMREC). Approval code: UM.TNC2/UMREC - 885

\section{Authors contribution}

All authors contributed to the study conception and design. Material preparation and analysis were performed by Li Ping Wong, Haridah Alias and Mahmoud Danaee. Data collection were performed by Lai Lee Lee, See Mee Hoong, Peter Seah Keng Tok and Ting Chuo Yew. The first draft of the manuscript was written by Li Ping Wong and all authors commented on previous versions of the manuscript. All authors read and approved the final manuscript.

\section{Conflict of Interest}

The authors declare that they have no conflict of interest.

\section{Consent to participate}

Informed consent was obtained from all individual participants included in the study. 


\section{Data availability}

The datasets generated during and/or analysed during the current study are available from the corresponding author on reasonable request.

\section{Acknowledgments}

The authors would like to thank Mrs Lim Chiou Ling, chairwomen of Candy Girls Breast Cancer Support Group University Malaya Medical Centre; Ms Ranjit Kaur, Chairman of Breast Cancer Welfare Association, Mr Peter Wong, Chairperson Exercise Support Group University Malaya Medical Centre ; ROSE Foundation; Prof Dr. Ong Teng Aik, Prof Dr. Woo Yin Ling and all cancer survivors for their contributions in the research project.

\section{References}

1. Chan JF, Yuan S, Kok KH, To KK, Chu H, Yang J, Xing F, Liu J, Yip CC, Poon RW, Tsoi HW. A familial cluster of pneumonia associated with the 2019 novel coronavirus indicating person-to-person transmission: a study of a family cluster. The Lancet. 2020 Feb 15;395(10223):514-23. doi: 10.1016/S0140-6736(20)30154-9

2. Wang C, Horby PW, Hayden FG, Gao GF. A novel coronavirus outbreak of global health concern. Lancet 395(10223),470-473. doi: 10.1016/S0140-6736(20)30185-9

3. WHO. Coronavirus disease 2019 (COVID-19) Situation Report - 71. 2020. https://www.who.int/docs/default-source/coronaviruse/situation-reports/20200331-sitrep-71-covid19.pdf?sfvrsn=4360e92b_8. Accessed 20 Julai 2020

4. Tsamakis K, Gavriatopoulou M, Schizas D, Stravodimou A, Mougkou A, Tsiptsios D, Sioulas V, Spartalis E, Sioulas AD, Tsamakis C, Charalampakis N. Oncology during the COVID-19 pandemic: challenges, dilemmas and the psychosocial impact on cancer patients. Oncology Letters. $2020 \mathrm{Jul}$ 1;20(1):441-7. https://doi.org/10.3892/ol.2020.11599

5. Al-Quteimat OM, Amer AM. The impact of the COVID-19 pandemic on cancer patients. American Journal of Clinical Oncology. 2020 Jun;43(6):452-455. doi: 10.1097/COC.0000000000000712;

6. Yeoh CB, Lee KJ, Rieth EF, Mapes R, Tchoudovskaia AV, Fischer GW, Tollinche LE. COVID-19 in the Cancer Patient. Anesthesia and Analgesia. 2020 Apr 22. doi: 10.1213/ANE.0000000000004884

7. Liang W, Guan W, Chen R, Wang W, Li J, Xu K, Li C, Ai Q, Lu W, Liang H, Li S. Cancer patients in SARSCoV-2 infection: a nationwide analysis in China. The Lancet Oncology. 2020 Mar 1;21(3):335-7. DOI:https://doi.org/10.1016/S1470-2045(20)30096-6

8. National Cancer Institute. The Malaysian National Cancer Registry Report (MNCR) 2007-2011. 2015. https://www.crc.gov.my/wp-content/uploads/documents/report/MNCRRrepor2007-2011.pdf. Accesed 20 July 2020.

9. Naughton MJ, Weaver KE. Physical and mental health among cancer survivors: considerations for long-term care and quality of life. North Carolina medical journal. 2014 Jul 1;75(4):283-6. 
10. Niedzwiedz CL, Knifton L, Robb KA, Katikireddi SV, Smith DJ. Depression and anxiety among people living with and beyond cancer: a growing clinical and research priority. BMC cancer. 2019 Dec;19(1):1-8. doi: 10.1186/s12885-019-6181-4

11. Dryhurst S, Schneider CR, Kerr J, Freeman AL, Recchia G, Van Der Bles AM, Spiegelhalter D, van der Linden S. Risk perceptions of COVID-19 around the world. Journal of Risk Research. 2020 May 5:1-3. https://doi.org/10.1080/13669877.2020.1758193

12. Becker MH. The Health Belief Model and personal health behavior. Health Education Monographs. 1974;2:324-508.

13. Rosenstock IM. Historical origins of the health belief model. Health education monographs. 1974 Dec;2(4):328-35.

14. Champion V, Skinner CS. The Health Belief Model. In: Glanz K, Rimer B, Viswanath K, editors. Health behavior and health education. 4. San Francisco, CA: Jossey-Bass; 2008. pp. 45-65. -65

15. Zigmond AS, Snaith RP. The hospital anxiety and depression scale. Acta psychiatrica scandinavica. 1983 Jun;67(6):361-70. doi: 10.1111/j.1600-0447.1983.tb09716.x.

16. Vodermaier A, Millman RD. Accuracy of the Hospital Anxiety and Depression Scale as a screening tool in cancer patients: a systematic review and meta-analysis. Supportive Care in Cancer. 2011 Dec 1;19(12):1899. DOI: 10.1007/s00520-011-1251-4

17. Chin WW. The partial least squares approach to structural equation modeling. Modern methods for business research. 1998;295:295-336.

18. Ringle CM, Wende S, Becker JM. SmartPLS 3. Boenningstedt: SmartPLS GmbH. 2015

19. Kline RB.Principles and practice of structural equation modeling. New York: Guilford Press. 2011

20. Frey MK, Ellis AE, Zeligs K, Chapman-Davis E, Thomas C, Christos PJ, Kolev V, Prasad-Hayes M, Cohen S, Holcomb K, Blank SV. Impact of the COVID-19 Pandemic on Quality of Life for Women with Ovarian Cancer. American journal of obstetrics and gynecology. 2020 Jun 26. doi:https://doi.org/10.1016/j.ajog.2020.06.049

21. Spicer J, Chamberlain C, Papa S. Provision of cancer care during the COVID-19 pandemic. Nature Reviews Clinical Oncology. 2020 Apr 15:1-3. doi: 10.1038/s41571-020-0370-6

22. Mercy Malaysia. Sokongan Psikososial Covid-19. 2020. https://www.mercy.org.my/popupbuilder/covid-19-hotline/mercy-malaysia-sokongan-psikososialcovid-19/. Accessed 20 July 2020.

23. Nelson CJ, Weinberger MI, Balk E, Holland J, Breitbart W, Roth AJ. The chronology of distress, anxiety, and depression in older prostate cancer patients. The oncologist. 2009 Sep;14(9):891. doi: 10.1634/theoncologist.2009-0059

24. Weiss Wiesel TR, Nelson CJ, Tew WP, Hardt M, Mohile SG, Owusu C, Klepin HD, Gross CP, Gajra A, Lichtman SM, Ramani R. The relationship between age, anxiety, and depression in older adults with cancer. Psycho-Oncology. 2015 Jun;24(6):712-7. doi: 10.1634/theoncologist.2009-0059. 
25. Inhestern L, Beierlein V, Bultmann JC, Möller B, Romer G, Koch U, Bergelt C. Anxiety and depression in working-age cancer survivors: a register-based study. BMC cancer. 2017 Dec;17(1):1-8. DOI: 10.1186/s12885-017-3347-9.

26. McLean CP, Asnaani A, Litz BT, Hofmann SG. Gender differences in anxiety disorders: prevalence, course of illness, comorbidity and burden of illness. Journal of psychiatric research. 2011 Aug 1;45(8):1027-35. DOI: 10.1016/j.jpsychires.2011.03.006.

27. Blbas HT, Aziz KF, Nejad SH, Barzinjy AA. Phenomenon of depression and anxiety related to precautions for prevention among population during the outbreak of COVID-19 in Kurdistan Region of Iraq: based on questionnaire survey. Journal of Public Health. 2020 Jun 10:1-5. https://doi.org/10.1007/s10389-020-01325-9.

28. Guo X, Meng Z, Huang G, Fan J, Zhou W, Ling W, Jiang J, Long J, Su L. Meta-analysis of the prevalence of anxiety disorders in mainland China from 2000 to 2015. Scientific reports. 2016 Jun 16;6(1):1-5. https://doi.org/10.1038/srep28033.

29. Varshney M, Parel JT, Raizada N, Sarin SK. Initial psychological impact of COVID-19 and its correlates in Indian Community: An online (FEEL-COVID) survey. Plos one. 2020 May 29;15(5):e0233874. doi:https://doi.org/10.1371/journal.pone.0233874,

30. Wong LP, Alias $\mathrm{H}$. Temporal changes in psychobehavioural responses during the early phase of the COVID-19 pandemic in Malaysia. Journal of Behavioral Medicine [in press]. 2020.

DOI: 10.21203/rs.3.rs-24316/v1

31. Bjelland I, Krokstad S, Mykletun A, Dahl AA, Tell GS, Tambs K. Does a higher educational level protect against anxiety and depression? The HUNT study. Social science \& medicine. $2008 \mathrm{Mar}$ 1;66(6):1334-45. DOI: 10.1016/j.socscimed.2007.12.019

32. Sareen J, Afifi TO, McMillan KA, Asmundson GJ. Relationship between household income and mental disorders: findings from a population-based longitudinal study. Archives of general psychiatry. 2011 Apr 4;68(4):419-27. doi:10.1001/archgenpsychiatry.2011.15

33. Akhtar-Danesh N, Landeen J. Relation between depression and sociodemographic factors. International journal of mental health systems. 2007 Dec 1;1(1):4. doi: https://doi.org/10.1186/17524458-1-4

34. Ruo B, Rumsfeld JS, Hlatky MA, Liu H, Browner WS, Whooley MA. Depressive symptoms and healthrelated quality of life: the Heart and Soul Study. Jama. 2003 Jul 9;290(2):215-21.

35. Beverly C, Pozehl B, Hertzog M, Zimmerman L, Riegel B. Predictors of overall perceived health in patients with heart failure. The Journal of cardiovascular nursing. 2013 May;28(3):206.

doi: $10.1097 / J C N .0 b 013 e 31824987 a 8$

\section{Tables}

Table 1 Participant characteristics by mean HAD-A, HAD-D and HAD-T scores ( $N=631)$ 


\begin{tabular}{|c|c|c|c|c|}
\hline \multirow{2}{*}{ Demograhics } & \multirow[t]{2}{*}{$\mathrm{N}(\%)$} & \multicolumn{3}{|c|}{$\begin{array}{l}\text { TotaL Score } \\
\text { (Mean } \pm S D)\end{array}$} \\
\hline & & HADS-A & HADS-D & HADS-T \\
\hline \multicolumn{5}{|l|}{ Age group } \\
\hline $21-49$ & $\begin{array}{l}160 \\
(25.4)\end{array}$ & $\begin{array}{l}5.72 \pm \\
4.05\end{array}$ & $\begin{array}{l}3.84 \pm \\
3.38\end{array}$ & $\begin{array}{l}9.56 \pm \\
7.02\end{array}$ \\
\hline $50-60$ & $\begin{array}{l}230 \\
(36.5)\end{array}$ & $\begin{array}{l}5.03 \pm \\
3.60\end{array}$ & $\begin{array}{l}3.96 \pm \\
3.50\end{array}$ & $\begin{array}{l}9.00 \pm \\
6.49\end{array}$ \\
\hline \multirow[t]{2}{*}{$61-86$} & $\begin{array}{l}241 \\
(38.2)\end{array}$ & $\begin{array}{l}5.90 \pm \\
3.95\end{array}$ & $\begin{array}{l}5.25 \pm \\
3.95\end{array}$ & $\begin{array}{l}11.15 \pm \\
7.33\end{array}$ \\
\hline & & 0.042 & $p<0.001$ & 0.003 \\
\hline \multicolumn{5}{|l|}{ Gender } \\
\hline Male & $\begin{array}{l}174 \\
(27.6)\end{array}$ & $\begin{array}{l}5.72 \pm \\
3.92\end{array}$ & $\begin{array}{l}5.51 \pm \\
3.86\end{array}$ & $\begin{array}{l}11.29 \pm \\
7.25\end{array}$ \\
\hline \multirow[t]{2}{*}{ Female } & $\begin{array}{l}457 \\
(72.4)\end{array}$ & $\begin{array}{l}5.47 \pm \\
3.85\end{array}$ & $\begin{array}{l}4.01 \pm \\
3.56\end{array}$ & $\begin{array}{l}9.48 \pm \\
6.86\end{array}$ \\
\hline & & 0.454 & $p<0.001$ & 0.005 \\
\hline \multicolumn{5}{|l|}{ Ethnicity } \\
\hline Malay & $\begin{array}{l}174 \\
(27.6)\end{array}$ & $\begin{array}{l}5.43 \pm \\
3.89\end{array}$ & $\begin{array}{l}4.18 \pm \\
3.75\end{array}$ & $\begin{array}{l}9.62 \pm \\
7.14\end{array}$ \\
\hline Chinese & $\begin{array}{l}332 \\
(52.6)\end{array}$ & $\begin{array}{l}5.09 \pm \\
3.76\end{array}$ & $\begin{array}{l}3.80 \pm \\
3.22\end{array}$ & $\begin{array}{l}8.89 \pm \\
6.42\end{array}$ \\
\hline Indian & $\begin{array}{l}31 \\
(4.9)\end{array}$ & $\begin{array}{l}6.58 \pm \\
4.24\end{array}$ & $\begin{array}{l}4.61 \pm \\
3.36\end{array}$ & $\begin{array}{l}11.19 \pm \\
7.08\end{array}$ \\
\hline \multirow[t]{2}{*}{ Indigenous of Sabah/Sarawak } & $\begin{array}{l}94 \\
(14.9)\end{array}$ & $\begin{array}{l}6.97 \pm \\
3.73\end{array}$ & $\begin{array}{l}7.01 \pm \\
4.25\end{array}$ & $\begin{array}{l}13.98 \pm \\
7.36\end{array}$ \\
\hline & & $p<0.001$ & $p<0.001$ & $p<0.001$ \\
\hline \multicolumn{5}{|l|}{ Highest educational level } \\
\hline Secondary school and below & $\begin{array}{l}225 \\
(35.7)\end{array}$ & $\begin{array}{l}6.28 \pm \\
3.83\end{array}$ & $\begin{array}{l}5.57 \pm \\
4.26\end{array}$ & $\begin{array}{l}11.86 \pm \\
7.54\end{array}$ \\
\hline \multirow[t]{2}{*}{ College/University } & $\begin{array}{l}406 \\
(64.3)\end{array}$ & $\begin{array}{l}5.12 \pm \\
3.83\end{array}$ & $\begin{array}{l}3.79 \pm \\
3.19\end{array}$ & $\begin{array}{l}8.91 \pm \\
6.47\end{array}$ \\
\hline & & $p<0.001$ & $p<0.001$ & $p<0.001$ \\
\hline \multicolumn{5}{|c|}{ Average monthly household income (MYR) } \\
\hline 4000 and below & 204 & $5.36 \pm$ & $4.69 \pm$ & $10.05 \pm$ \\
\hline
\end{tabular}




\begin{tabular}{|c|c|c|c|c|}
\hline & (32.3) & 3.84 & 3.96 & 7.22 \\
\hline $4001-8000$ & $\begin{array}{l}275 \\
(43.6)\end{array}$ & $\begin{array}{l}6.17 \pm \\
3.92\end{array}$ & $\begin{array}{l}4.85 \pm \\
3.76\end{array}$ & $\begin{array}{l}11.02 \pm \\
7.21\end{array}$ \\
\hline \multirow[t]{2}{*}{$>8000$} & $\begin{array}{l}152 \\
(24.1)\end{array}$ & $\begin{array}{l}4.63 \pm \\
3.60\end{array}$ & $\begin{array}{l}3.29 \pm \\
2.95\end{array}$ & $\begin{array}{l}7.92 \pm \\
5.87\end{array}$ \\
\hline & & $p<0.001$ & $p<0.001$ & $p<0.001$ \\
\hline \multicolumn{5}{|l|}{ Cancer characteristics } \\
\hline \multicolumn{5}{|c|}{ Time since diagnossis (years) } \\
\hline 4 and below & $\begin{array}{l}254 \\
(40.3)\end{array}$ & $\begin{array}{l}5.46 \pm \\
3.66\end{array}$ & $\begin{array}{l}3.89 \pm \\
3.29\end{array}$ & $\begin{array}{l}9.35 \pm \\
6.36\end{array}$ \\
\hline $5-9$ & $\begin{array}{l}256 \\
(40.6)\end{array}$ & $\begin{array}{l}5.76 \pm \\
4.31\end{array}$ & $\begin{array}{l}4.80 \pm \\
3.97\end{array}$ & $\begin{array}{l}10.56 \pm \\
7.80\end{array}$ \\
\hline \multirow[t]{2}{*}{10 years and above } & $\begin{array}{l}121 \\
(19.1)\end{array}$ & $\begin{array}{l}5.22 \pm \\
3.23\end{array}$ & $\begin{array}{l}4.75 \pm \\
3.83\end{array}$ & $\begin{array}{l}9.98 \pm \\
6.48\end{array}$ \\
\hline & & 0.415 & 0.012 & 0.151 \\
\hline \multicolumn{5}{|l|}{ Type of cancer } \\
\hline Breast & $\begin{array}{l}390 \\
(61.8)\end{array}$ & $\begin{array}{l}5.13 \pm \\
3.76\end{array}$ & $\begin{array}{l}3.64 \pm \\
3.23\end{array}$ & $\begin{array}{l}8.76 \pm \\
6.42\end{array}$ \\
\hline Prostate & $\begin{array}{l}164 \\
(26.0)\end{array}$ & $\begin{array}{l}5.73 \pm \\
3.85\end{array}$ & $\begin{array}{l}5.63 \pm \\
3.84\end{array}$ & $\begin{array}{l}11.37 \pm \\
7.16\end{array}$ \\
\hline Bladder & $\begin{array}{l}22 \\
(3.5)\end{array}$ & $\begin{array}{l}11.14 \pm \\
2.49\end{array}$ & $\begin{array}{l}11.41 \pm \\
2.81\end{array}$ & $\begin{array}{l}22.55 \pm \\
4.87\end{array}$ \\
\hline Ovarian & $\begin{array}{l}13 \\
(2.1)\end{array}$ & $\begin{array}{l}6.69 \pm \\
3.95\end{array}$ & $\begin{array}{l}5.85 \pm \\
3.41\end{array}$ & $\begin{array}{l}12.54 \pm \\
6.40\end{array}$ \\
\hline Cervical & $\begin{array}{l}12 \\
(1.9)\end{array}$ & $\begin{array}{l}5.00 \pm \\
3.02\end{array}$ & $\begin{array}{l}3.58 \pm \\
2.78\end{array}$ & $\begin{array}{l}8.58 \pm \\
5.28\end{array}$ \\
\hline Nasopharyngeal & $8(1.3)$ & $\begin{array}{l}4.63 \pm \\
3.89\end{array}$ & $\begin{array}{l}3.00 \pm \\
1.69\end{array}$ & $\begin{array}{l}7.63 \pm \\
5.45\end{array}$ \\
\hline Lymphoma & $7(1.1)$ & $\begin{array}{l}6.29 \pm \\
3.50\end{array}$ & $\begin{array}{l}2.43 \pm \\
2.57\end{array}$ & $\begin{array}{l}8.71 \pm \\
5.85\end{array}$ \\
\hline Colon & $5(0.8)$ & $\begin{array}{l}6.00 \pm \\
1.41\end{array}$ & $\begin{array}{l}3.40 \pm \\
0.89\end{array}$ & $\begin{array}{l}9.40 \pm \\
2.19\end{array}$ \\
\hline Appendix & $4(0.6)$ & $\begin{array}{l}5.50 \pm \\
3.00\end{array}$ & $\begin{array}{l}1.75 \pm \\
1.50\end{array}$ & $\begin{array}{l}7.25 \pm \\
1.50\end{array}$ \\
\hline \multirow[t]{2}{*}{ Others } & $6(1.0)$ & $\begin{array}{l}5.00 \pm \\
4.20\end{array}$ & $\begin{array}{l}2.33 \pm \\
2.58\end{array}$ & $\begin{array}{l}7.33 \pm \\
6.59\end{array}$ \\
\hline & & $p<0.001$ & $p<0.001$ & $p<0.001$ \\
\hline
\end{tabular}


Stage of cancer at the time of first diagnosis

\begin{tabular}{|c|c|c|c|c|}
\hline 0 & $\begin{array}{l}41 \\
(6.5)\end{array}$ & $\begin{array}{l}3.76 \pm \\
2.76\end{array}$ & $\begin{array}{l}2.66 \pm \\
2.73\end{array}$ & $\begin{array}{l}6.42 \pm \\
4.88\end{array}$ \\
\hline 1 & $\begin{array}{l}190 \\
(30.1)\end{array}$ & $\begin{array}{l}4.92 \pm \\
3.65\end{array}$ & $\begin{array}{l}4.04 \pm \\
3.22\end{array}$ & $\begin{array}{l}8.96 \pm \\
6.38\end{array}$ \\
\hline 2 & $\begin{array}{l}246 \\
(39.0)\end{array}$ & $\begin{array}{l}5.82 \pm \\
3.71\end{array}$ & $\begin{array}{l}4.83 \pm \\
4.08\end{array}$ & $\begin{array}{l}10.65 \pm \\
7.23\end{array}$ \\
\hline 3 & $\begin{array}{l}123 \\
(19.5)\end{array}$ & $\begin{array}{l}6.17 \pm \\
4.10\end{array}$ & $\begin{array}{l}4.72 \pm \\
3.82\end{array}$ & $\begin{array}{l}10.89 \pm \\
7.43\end{array}$ \\
\hline \multirow[t]{2}{*}{4} & $\begin{array}{l}31 \\
(4.9)\end{array}$ & $\begin{array}{l}6.94 \pm \\
5.29\end{array}$ & $\begin{array}{l}4.71 \pm \\
3.25\end{array}$ & $\begin{array}{l}11.65 \pm \\
7.67\end{array}$ \\
\hline & & $p<0.001$ & 0.004 & $p<0.001$ \\
\hline \multicolumn{5}{|c|}{ Type of treatment received } \\
\hline \multicolumn{5}{|c|}{ Surgery } \\
\hline Yes & $\begin{array}{l}571 \\
(90.5)\end{array}$ & $\begin{array}{l}5.56 \pm \\
3.83\end{array}$ & $\begin{array}{l}4.49 \pm \\
3.76\end{array}$ & $\begin{array}{l}10.05 \pm \\
7.02\end{array}$ \\
\hline \multirow[t]{2}{*}{ No } & $\begin{array}{l}60 \\
(9.5)\end{array}$ & $\begin{array}{l}5.32 \pm \\
4.18\end{array}$ & $\begin{array}{l}3.78 \pm \\
3.05\end{array}$ & $\begin{array}{l}9.10 \pm \\
6.92\end{array}$ \\
\hline & & 0.643 & 0.160 & 0.318 \\
\hline \multicolumn{5}{|c|}{ Chemotherapy } \\
\hline Yes & $\begin{array}{l}404 \\
(64.0)\end{array}$ & $\begin{array}{l}6.12 \pm \\
3.92\end{array}$ & $\begin{array}{l}4.96 \pm \\
3.96\end{array}$ & $\begin{array}{l}11.08 \pm \\
7.26\end{array}$ \\
\hline \multirow[t]{2}{*}{ No } & $\begin{array}{l}227 \\
(36.0)\end{array}$ & $\begin{array}{l}4.51 \pm \\
3.55\end{array}$ & $\begin{array}{l}3.47 \pm \\
2.97\end{array}$ & $\begin{array}{l}7.97 \pm \\
6.06\end{array}$ \\
\hline & & $p<0.001$ & $p<0.001$ & $p<0.001$ \\
\hline \multicolumn{5}{|c|}{ Radiotherapy } \\
\hline Yes & $\begin{array}{l}394 \\
(62.4)\end{array}$ & $\begin{array}{l}5.96 \pm \\
3.89\end{array}$ & $\begin{array}{l}4.91 \pm \\
3.97\end{array}$ & $\begin{array}{l}10.87 \pm \\
7.31\end{array}$ \\
\hline \multirow[t]{2}{*}{ No } & $\begin{array}{l}237 \\
(37.6)\end{array}$ & $\begin{array}{l}4.84 \pm \\
3.73\end{array}$ & $\begin{array}{l}3.62 \pm \\
3.05\end{array}$ & $\begin{array}{l}8.46 \pm \\
6.20\end{array}$ \\
\hline & & $p<0.001$ & $p<0.001$ & $p<0.001$ \\
\hline \multicolumn{5}{|c|}{ Endocrine therapy } \\
\hline Yes & $\begin{array}{l}209 \\
(33.1)\end{array}$ & $\begin{array}{l}5.62 \pm \\
3.71\end{array}$ & $\begin{array}{l}5.29 \pm \\
3.71\end{array}$ & $\begin{array}{l}10.91 \pm \\
6.84\end{array}$ \\
\hline No & $\begin{array}{l}422 \\
(66.9)\end{array}$ & $\begin{array}{l}5.50 \pm \\
3.95\end{array}$ & $\begin{array}{l}3.99 \pm \\
3.63\end{array}$ & $\begin{array}{l}9.49 \pm \\
7.05\end{array}$ \\
\hline
\end{tabular}




\section{$0.715 \quad p<0.001 \quad 0.017$}

Targeted therapy

\begin{tabular}{|c|c|c|c|c|}
\hline Yes & $\begin{array}{l}77 \\
(12.2)\end{array}$ & $\begin{array}{l}6.00 \pm \\
4.60\end{array}$ & $\begin{array}{l}4.55 \pm \\
3.82\end{array}$ & $\begin{array}{l}10.55 \pm \\
7.75\end{array}$ \\
\hline \multirow[t]{2}{*}{ No } & $\begin{array}{l}554 \\
(87.8)\end{array}$ & $\begin{array}{l}5.47 \pm \\
3.75\end{array}$ & $\begin{array}{l}4.41 \pm \\
3.69\end{array}$ & $\begin{array}{l}9.88 \pm \\
6.91\end{array}$ \\
\hline & & 0.263 & 0.757 & 0.435 \\
\hline \multicolumn{5}{|c|}{ Alternative therapy } \\
\hline Yes & $\begin{array}{l}44 \\
(7.0)\end{array}$ & $\begin{array}{l}5.96 \pm \\
3.85\end{array}$ & $\begin{array}{l}4.09 \pm \\
3.03\end{array}$ & $\begin{array}{l}10.05 \pm \\
6.44\end{array}$ \\
\hline \multirow[t]{2}{*}{ No } & $\begin{array}{l}587 \\
(93.0)\end{array}$ & $\begin{array}{l}5.51 \pm \\
3.87\end{array}$ & $\begin{array}{l}4.45 \pm \\
3.75\end{array}$ & $\begin{array}{l}9.95 \pm \\
7.06\end{array}$ \\
\hline & & 0.458 & 0.538 & 0.934 \\
\hline
\end{tabular}

Comorbidities

Diagnosed with other comorbidities

$\begin{array}{lllll}\text { Yes } & 200 & 6.39 \pm & 5.76 \pm & 12.15 \pm \\ \text { No } & (31.7) & 4.09 & 4.23 & 7.71 \\ & 431 & 5.14 \pm & 3.81 \pm & 8.95 \pm \\ & (68.3) & 3.70 & 3.26 & 6.42 \\ & & p<0.001 & p<0.001 & p<0.001\end{array}$

Overall health status

Self-perceived overall health status

$\begin{array}{lllll}\text { Excellent } & 84 & 2.73 \pm & 1.81 \pm & 4.54 \pm \\ \text { Good } & (13.3) & 2.92 & 2.44 & 4.89 \\ & 314 & 4.83 \pm & 3.37 \pm & 8.19 \pm \\ \text { Fair } & (49.8) & 3.42 & 2.93 & 5.74 \\ & 202 & 7.04 \pm & 5.97 \pm & 13.01 \pm \\ \text { Poor } & (32.0) & 3.55 & 3.10 & 6.03 \\ & 31 & 10.58 \pm & 12.13 \pm & 22.71 \pm \\ & (4.9) & 3.84 & 3.12 & 5.77 \\ & & p<0.001 & p<0.001 & p<0.001\end{array}$

Health belief model

Perceived susceptibility

My chance of getting coronavirus disease in the next few months is great 
Strongly agree/ Agree

Strongly disagree/Disagree

$\begin{array}{llll}337 & 6.21 \pm & 5.15 \pm & 11.37 \pm \\ (53.4) & 3.98 & 4.04 & 7.52 \\ 294 & 4.76 \pm & 3.59 \pm & 8.35 \pm \\ (46.6) & 3.59 & 3.08 & 6.00 \\ & p<0.001 & p<0.001 & p<0.001\end{array}$

I am worried about the likelihood of getting coronavirus disease

Strongly agree/ Agree

Strongly disagree/Disagree

\begin{tabular}{llll}
442 & $6.24 \pm$ & $5.01 \pm$ & $11.25 \pm$ \\
$(70.0)$ & 3.89 & 3.87 & 7.23 \\
\hline 189 & $3.89 \pm$ & $3.05 \pm$ & $6.95 \pm$ \\
$(30.0)$ & 3.26 & 2.86 & 5.40 \\
& $p<0.001$ & $p<0.001$ & $p<0.001$
\end{tabular}

Getting coronavirus disease is currently a possibility for me.

Strongly agree/ Agree

Strongly disagree/Disagree

$\begin{array}{llll}364 & 6.37 \pm & 5.32 \pm & 11.69 \pm \\ (57.7) & 3.97 & 3.94 & 7.41 \\ 267 & 4.40 \pm & 3.20 \pm & 7.60 \pm \\ (42.3) & 3.41 & 29.4 & 5.63 \\ & p<0.001 & p<0.001 & p<0.001 \\ & & & \end{array}$

Perceived severity

Complications from coronavirus disease are serious

Strongly agree/ Agree

\begin{tabular}{llll}
604 & $5.66 \pm$ & $4.53 \pm$ & $10.19 \pm$ \\
$(95.7)$ & 3.85 & 3.72 & 7.00 \\
\hline 27 & $2.82 \pm$ & $2.08 \pm$ & $4.89 \pm$ \\
$(4.3)$ & 3.13 & 2.42 & 5.29 \\
& $p<0.001$ & 0.001 & $p<0.001$
\end{tabular}

I will be very sick if I get coronavirus disease

Strongly agree/ Agree

$\begin{array}{llll}523 & 5.91 \pm & 4.84 \pm & 10.74 \pm \\ (82.9) & 3.89 & 3.75 & 7.06 \\ 108 & 3.74 \pm & 2.44 \pm & 6.18 \pm \\ (17.1) & 3.22 & 2.68 & 5.39 \\ & p<0.001 & p<0.001 & p<0.001\end{array}$

I am afraid of getting coronavirus disease

Strongly agree/ Agree

$\begin{array}{llll}565 & 5.81 \pm & 4.64 \pm & 10.45 \pm \\ (89.5) & 3.85 & 3.77 & 7.04 \\ 66 & 3.23 \pm & 2.58 \pm & 5.80 \pm \\ (10.5) & 3.16 & 2.40 & 5.13\end{array}$




\section{Figures}

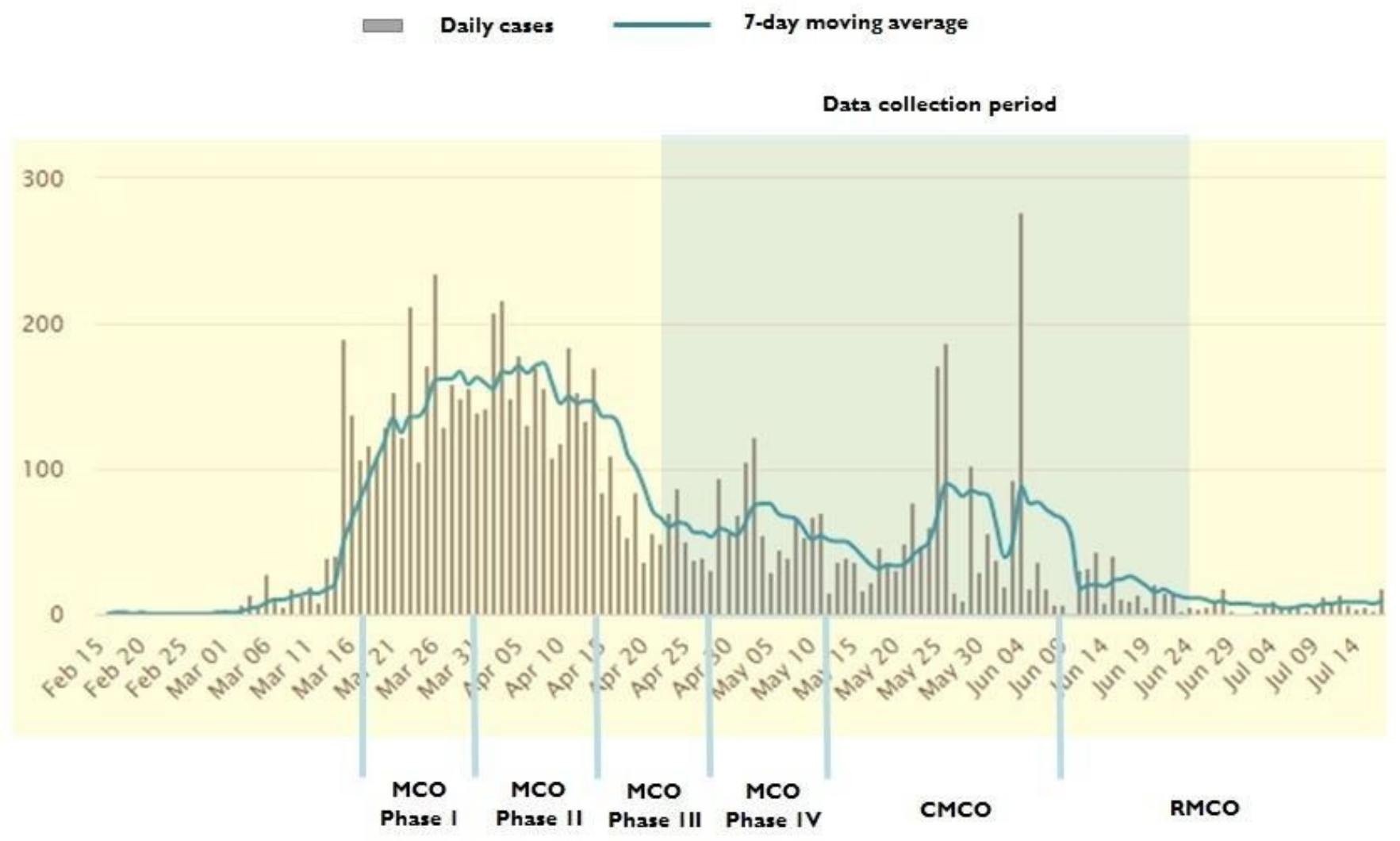

\section{Figure 1}

Data collection period of the survey, confirmed cases of COVID-19 in Malaysia, and stages of Movement Control Orders in Malaysia. 


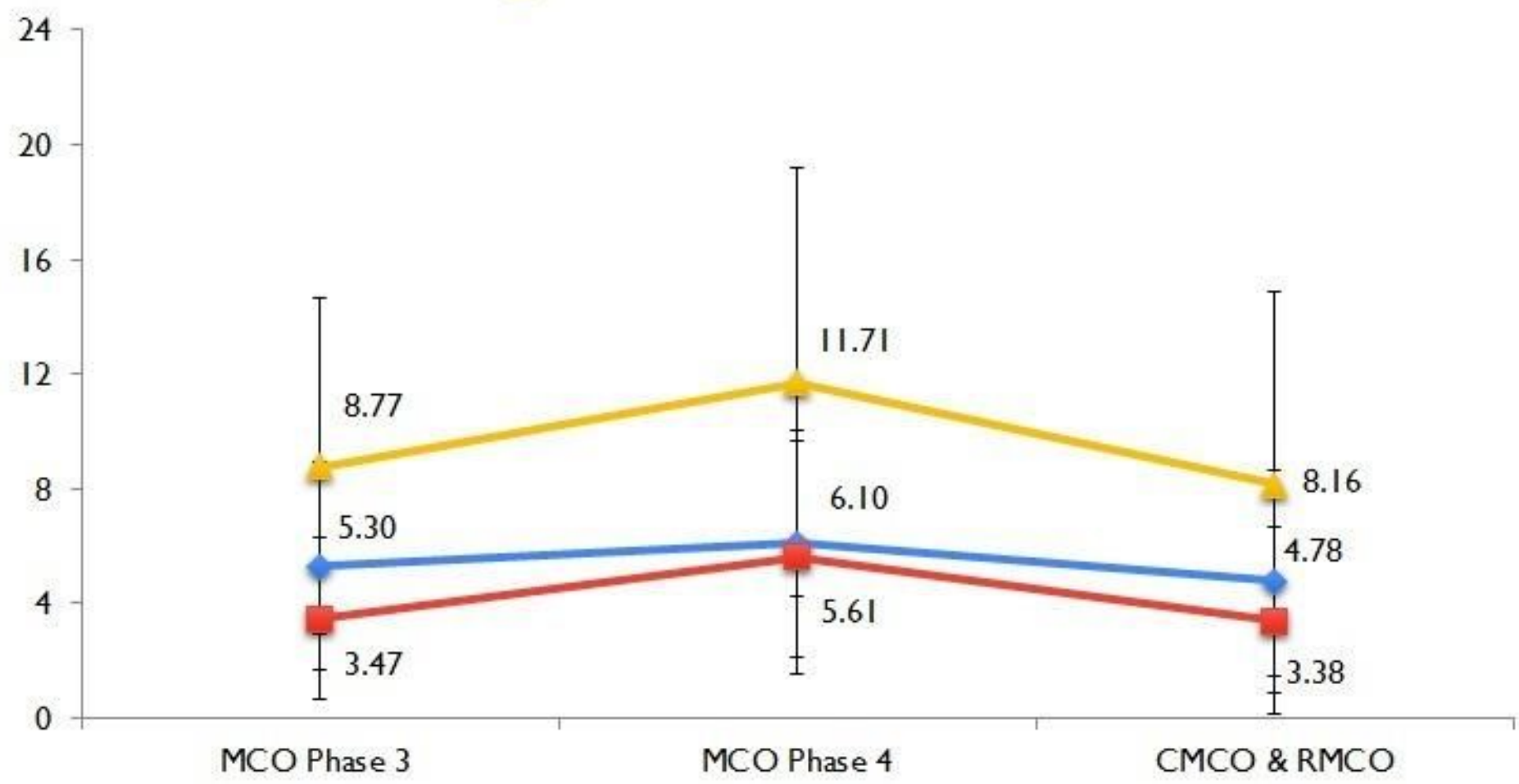

Figure 2

The trend line of mean HAD-A, HAD-D and HAD-T scores across the phases of Movement Control Order in Malaysia 


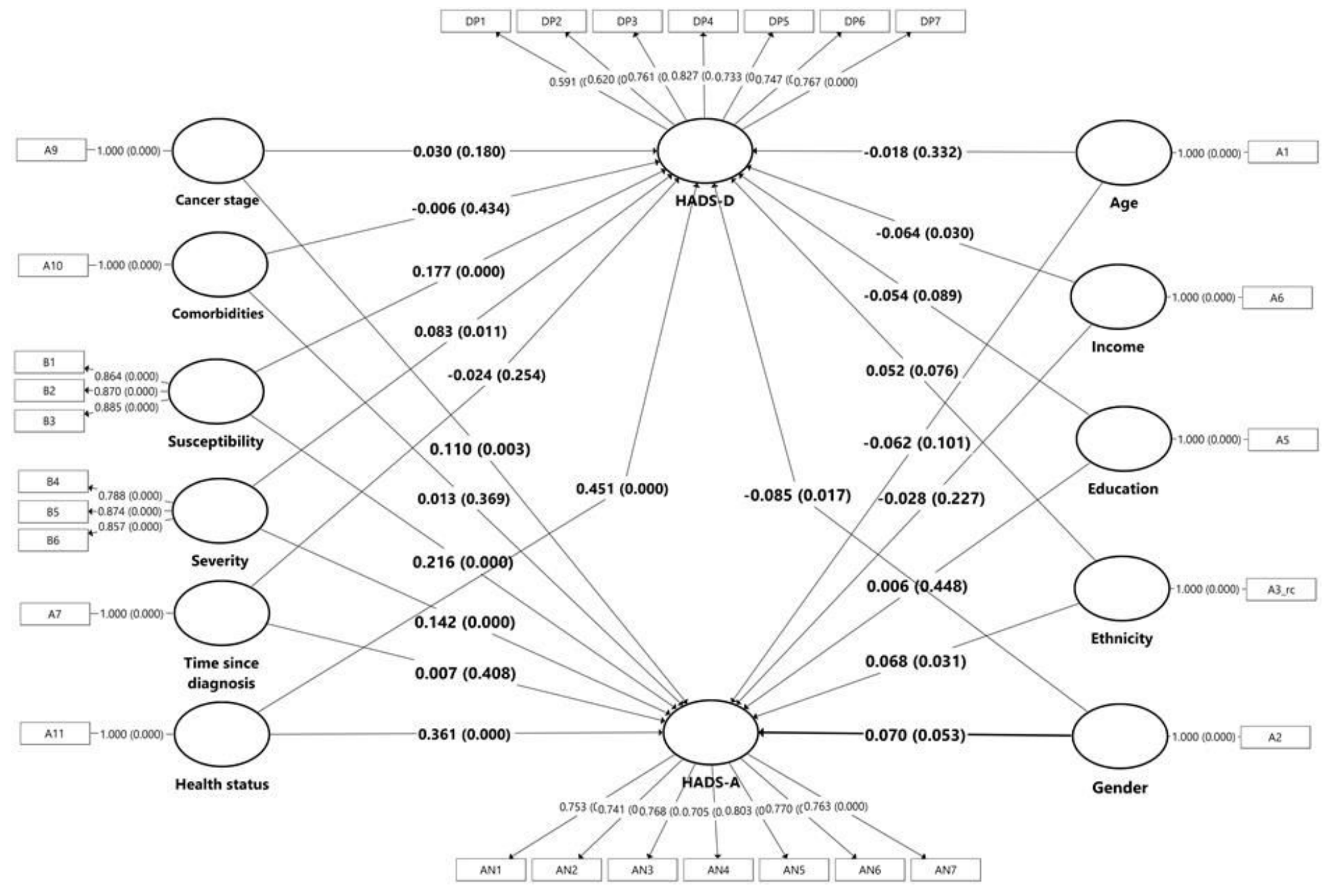

Figure 3

The Partial Least Square-Structural Equation Modelling (PLS-SEM) model of factors influences HADS-A and HADS-D. 


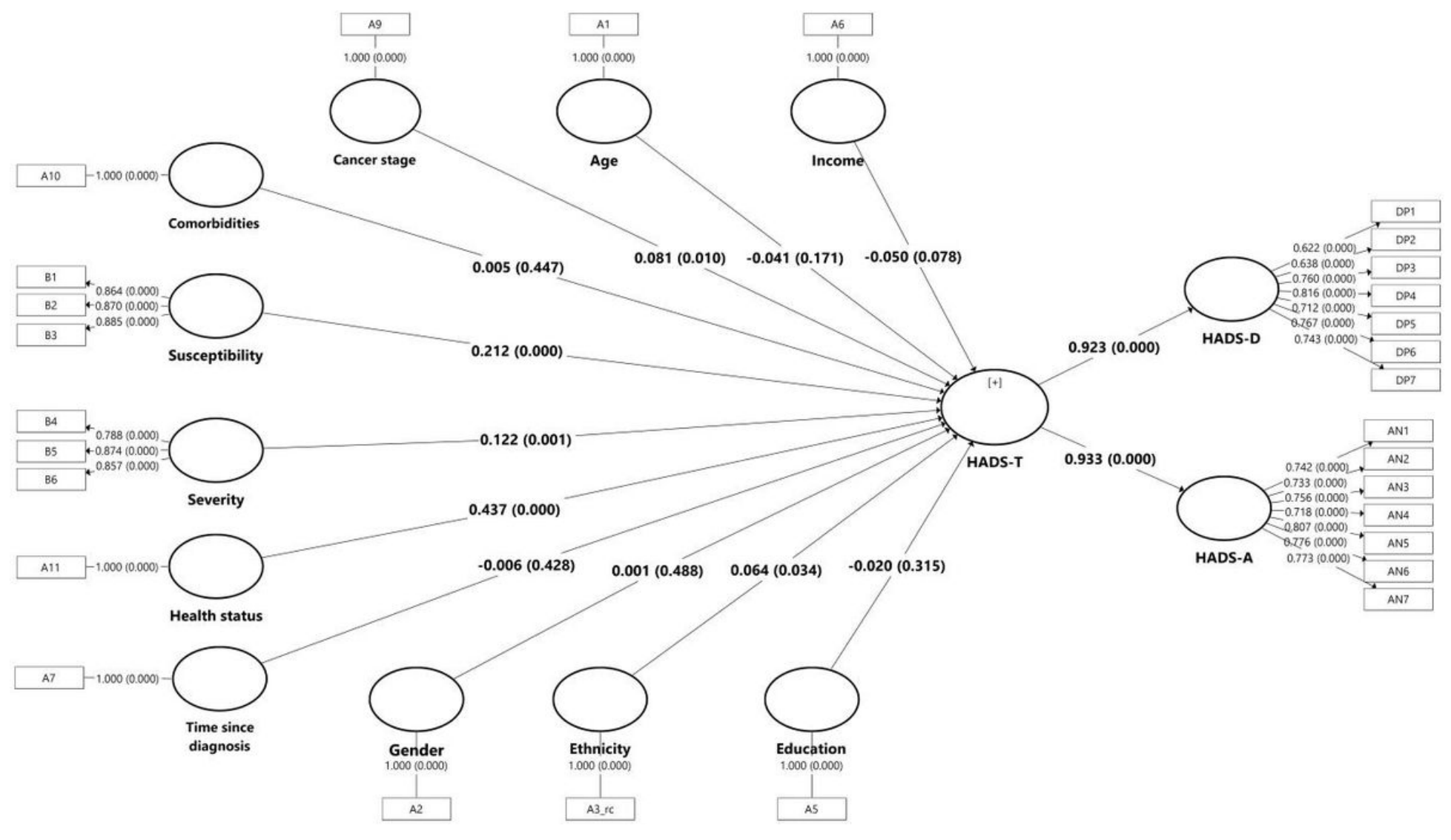

Figure 4

The Partial Least Square-Structural Equation Modelling (PLS-SEM) model of factors influence HADS-T 